\title{
Regulation of restrictocin production in Aspergillus restrictus
}

\author{
Rong YaNG and William R. KenEALY* \\ Department of Biochemistry, 420 Henry Mall, College of Agricultural and Life Sciences, University of Wisconsin, \\ Madison, Wisconsin 53706, USA
}

(Received 19 November 1991; revised 5 March 1992; accepted 31 March 1992)

\begin{abstract}
The production of restrictocin (a cytotoxin that specifically cleaves ribosomal RNA) by cultures of Aspergillus restrictus grown in liquid medium was investigated. The function of restrictocin, the method of its accumulation and the mode of resistance to restrictocin in $\boldsymbol{A}$. restrictus are unknown. Previous studies have indicated that restrictocin accumulates in the medium with culture age. These observations have been extended in this study by cloning the cDNA of the res gene and using this cDNA clone to probe the onset of messenger RNA synthesis in the cells. The results of the Northern analysis were compared to the production and accumulation of restrictocin and morphological differentiation of the cells in culture. Restrictocin was found in the medium at the same time that mRNA was detected in the cells. This suggests that the leader sequence encoded by the cDNA provides an efficient secretion system for the protein. Both the protein and the mRNA were detected coincident with the formation of differentiated cell structures. These structures develop into conidiophores with one layer of sterigmata and conidia forming from the sterigmata. These results suggest that restrictocin is either involved in the process of conidiation or is coordinately regulated with differentiation leading to conidiation.
\end{abstract}

\section{Introduction}

Restrictocin is a small basic protein $\left(M_{\mathrm{r}}\right.$ 17000), produced by Aspergillus restrictus, that inactivates ribosomes (Olson et al., 1963). This protein, along with an almost identical protein, mitogillin (from $A$. restrictus), and another similar protein, $\alpha$-sarcin (from Aspergillus giganteus), have anti-tumour activity (Olson et al., 1965). This anti-tumour activity appears to be due to the ability of restrictocin to enter cells and inactivate ribosomes. While these proteins showed promise in canine cancer tests (Roga et al., 1971) they were not effective in human cancer trials due to non-specific toxicity (Wool, 1984; Goldin et al., 1966).

Restrictocin, mitogillin and $\alpha$-sarcin act as ribonucleases which cleave a single specific phosphodiester bond 393 nucleotides from the $3^{\prime}$ end of the $28 \mathrm{~S}$ rRNA of eukaryotic ribosomes (Fando et al., 1985; Schindler \& Davies, 1977). The cleavage site is located in a highly conserved region of $28 \mathrm{~S}$ rRNA and this region is also the target site of some other ribosome-inactivating proteins such as ricin (Sperti et al., 1989).

$\alpha$-Sarcin acts in vitro on the ribosomes from $A$.

- Author for correspondence. Tel. (608) 263 4392; fax (608) 2623453. giganteus which produces $\alpha$-sarcin (Miller \& Bodley, 1988), raising the question of how the protein is formed. Several mechanisms could be employed by the fungus to produce a ribosome-inactivating protein. A protein or other substance could bind restrictocin to inactivate it, as is the case for colicin E3 and the immunity protein in Escherichia coli (Jakes \& Zinder, 1974), or the synthesis of restrictocin might be via an inactive proprotein. An efficient translocation signal peptide could also remove the protein away from the site of its synthesis. A recent report comparing the genomic sequence of restrictocin to the cDNA sequence of $\alpha$-sarcin suggested that the immature restrictocin does not have activity (Lamy \& Davies, 1991). How these ribosome-inactivating proteins are produced by Aspergillus and why they are produced are questions that remain unanswered.

A recent study showed that a restrictocin-like protein could be the cause of inflammation and local cell death in Aspergillosis infections (Arruda et al., 1990). If the function of restrictocin is to aid in the proliferation of the fungus in the lungs, it is important to know when and where the protein is made. A role in pathogenesis might be suggested for this protein if it were present on conidia or formed early upon germination. Alternative hypotheses are that restrictocin may bestow some survival advantage or be involved in the differentiation of cells. 
We report here that the cDNA sequence which encodes restrictocin does encode a putative translocation signal sequence. We find that the simultaneous appearance of mRNA in the cells and protein accumulation in the medium limits any possible protein storage and interactions at a later stage in the fungal life cycle. Accumulation of the protein in the medium and the presence of mRNA in the cells is correlated with the appearance in liquid medium of differentiated cells involved in conidiation. The timing of restrictocin production appears to be similar to that of other secondary metabolites by filamentous fungi.

\section{Methods}

Culture of organism. A. restrictus (strain NRRL 2869) was maintained on complete medium agar plates (Cove, 1966). Conidia from the agar plates were used to inoculate liquid media. Liquid cultures were grown at $30^{\circ} \mathrm{C}$ with constant shaking.

Purification of restrictocin and antibody production. A. restrictus was grown in 30 litres of medium C according to Olson et al. (1965). After $60 \mathrm{~h}$ incubation, the culture supernatant was used for purification of restrictocin with an IRC-50 ion-exchange column, also as described by Olson et al. (1965). Further purification of the protein was accomplished (for the generation of antibodies) by passing the column fractions through a $30 \mathrm{kDa}$ Millipore Pellicon filter and concentrating on a $10 \mathrm{kDa}$ filter; the concentrate was lyophilized and stored at $-20^{\circ} \mathrm{C}$. During purification, the protein was characterized by $12 \%$ $(w / v)$ polyacrylamide SDS gel electrophoresis (Laemmli, 1970) followed by silver staining (Wray et al., 1981).

Anti-restrictocin rabbit serum was produced at Promega. Purified protein $(0.5 \mathrm{mg})$ in complete Freund's adjuvant was injected initially and the same amount of antigen in incomplete Freund's adjuvant was used for the second and final boosts at 3 and 5.5 weeks. The antibody was characterized by its ability to bind to antigen on Microtiter plates (ELISA) and immunoblots. In the ELISA, $100 \mu \mathrm{l}\left[2.5 \mu \mathrm{g}\right.$ protein $\mathrm{ml}^{-1}$ in phosphate-buffered saline (10 mM-sodium phosphate, $150 \mathrm{~mm}$ $\mathrm{NaCl}$ ), $\mathrm{pH} 7 \cdot 4$ ] of antigen were used to coat each well at $4{ }^{\circ} \mathrm{C}$ overnight. The wells were blocked with $1 \%(\mathrm{v} / \mathrm{v})$ goat serum in PBST (phosphatebuffered saline, $0.05 \%$ Tween 20 , pH 7.4) after which $100 \mu$ l of diluted anti-restrictocin serum were added to each well and incubated for $1 \mathrm{~h}$ at room temperature. Incubation with the alkaline phosphatase-conjugated goat anti-rabbit IgG (Kirkegaard \& Perry Laboratories) was done under the same conditions and the colour developed for $30 \mathrm{~min}$ at room temperature using $o$-nitrophenyl phosphate as substrate. The absorbance at $405 \mathrm{~nm}$ was measured on a microplate reader (Bio-Tek).

cDNA and subgenomic DNA library construction and screening. PolyA-rich mRNA from $A$. restrictus was prepared by total nucleic acid extraction followed by oligo-dT affinity column purification (Ausubel et al., 1987). The BRL cDNA synthesis system was used to synthesize double stranded cDNA from the mRNA and recombinant dgt11 phages were produced by in vitro packaging and then plated on $E$. coli Y1088 to establish the cDNA library (BRL manual).

About $5 \%$ of the original cDNA library ( 5000 plaques $/ 4$ plates) was screened using plaque lifts, anti-restrictocin antibody and alkalinephosphatase-labelled goat anti-rabbit second antibody (Ausubel $e t$ al., 1987). Positive clones were confirmed by their ability to hybridize with a synthetic 32-fold degenerate probe which was derived from amino acids 46 to 51 of the reported protein sequence (Lopez-Otin et al., 1984).
Positive clones were plaque-purified twice and the insert fragment was subcloned into the EcoRI site of M13mp18.

A subgenomic DNA library was also constructed by ligating $5 \mathrm{~kb}$ fragments of EcoRI-digested DNA and EcoRI-cut $\lambda \mathrm{gt} 11$ and the recombinant phages were introduced into $E$. coli Y1088 as described above to generate a subgenomic library. The whole library (about 40000 plaques) was screened using the synthetic probe as described above. Three positive clones were observed and plaque-purified. The insert fragment was regenerated from phage DNA and proved to contain the restrictocin gene by Southern analysis using restrictocin cDNA as a probe.

Sequence analysis of the clones containing the restrictocin gene. Two M13 clones with the cDNA inserted in opposite orientations were used along with an M13 primer to sequence the insert DNA as described by Sanger et al. (1977). The sequence reported here was the result of at least two sequencing reactions for each subclone. The sequences of restrictocin and $\alpha$-sarcin were compared using the GAP program from the Genetics Computing Group (Madison, WI).

The cloned genomic restrictocin gene was regenerated, digested with several different restriction enzymes and analysed on agarose gel to obtain a partial restriction map. The EcoRI-XmaI and the XmaIHindIII fragments, which contain the entire coding region of the restrictocin gene, were subcloned into both $\mathrm{M} 13 \mathrm{mp} 18$ and $\mathrm{M} 13 \mathrm{mp} 19$. The upstream section of the transcription initiation region was cloned by screening a subgenomic library of $4.5 \mathrm{~kb} \mathrm{SacI}$ fragments (in plasmid pUC19) and the SacI-EcoRI fragment containing the upstream region was subcloned into M13mp18 and M13mp19. Sequence analysis on both strands was done as described above.

Northern analysis of $m R N A$. Total RNA was extracted from $A$. restrictus at different times of growth in complete fungal medium. The same amount of RNA (determined as $A_{260}$ ) from each sample was loaded onto a $1.2 \%(w / v)$ denaturing formaldehyde agarose gel and the relative amount of total RNA in each lane was estimated from a photograph of the ethidium-bromide-stained gel by densitometric analysis. Northern analysis was done by using the purified cloned gene fragment as a nick-translated probe (Promega manual). Prehybridization and hybridization were performed at $40^{\circ} \mathrm{C}$ in the presence of $50 \%$ (v/v) formamide (Ausubel et al., 1987) and the blot was exposed to Kodak X-OMAT AR film.

Immunoblot analysis of restrictocin. Culture samples were taken throughout incubation. The medium was separated from the cells by centrifugation. Supernatant was mixed with SDS sample buffer $(0 \cdot 125 \mathrm{~m}$-Tris, $2 \%, \mathrm{w} / \mathrm{v}$, SDS, $10 \% \mathrm{v} / \mathrm{v}$, glycerol, $5 \%, \mathrm{v} / \mathrm{v}, \beta$ mercaptoethanol) in a $1: 1$ ratio. The cells were washed with water and extracted with SDS sample buffer $(0 \cdot 1 \mathrm{mg}$ cell per $\mathrm{ml}$ of buffer). All samples were placed in a boiling water bath for 10 minutes followed by centrifugation and application of the supernatant to the gel. After gel electrophoresis, an immunoblot was made by using a semi-dry electrophoretic transfer unit (Gelman). The blot was stained with amido black and blocked in $5 \%(\mathrm{w} / \mathrm{v})$ powdered dry milk in phosphatebuffered saline. Anti-restrictocin antibody and alkaline-phosphataselabelled goat anti-rabbit second antibody were used for detection of restrictocin (Ausubel et al., 1987).

Microscopy. Samples were taken from the cultures throughout the incubation period for observation by phase contrast and differential interference contrast microscopy. Photomicrographs were taken with a Zeiss Axiophot photomicroscope using wet mounts of the hyphal material.

Nucleotide sequence accession numbers. The cDNA and genomic DNA sequences have been assigned GenBank accession numbers M55508 and M65257. 


\section{Results and Discussion}

Protein identification and antibody generation

The protein purified according to the method of Olson $e t$ al. (1965) from 30 liters of medium (estimated $>98 \%$ pure from silver-stained polyacrylamide gels) (Fig. 1) was tested for its ability to inhibit an in vitro protein translation system (Promega; rabbit reticulocyte incorporation of $\left[{ }^{35} \mathrm{~S}\right]$ methionine into acid-precipitible counts). The purified protein preparation was similar in its ability to inhibit protein synthesis to the restrictocin preparation reported by Fando et al. (1985). Since the protein was of the correct size and activity, we concluded that the protein purified was restrictocin and proceeded to use the protein for antibody generation.

Antibodies generated in rabbit against this protein were present 4 weeks after the first injection. The serum at that time reacted with $M_{\mathrm{r}} 17000$ and $M_{\mathrm{r}} 30000$ proteins on immunoblots and this reaction was not present in the pre-immune serum. The $M_{\mathrm{r}} 30000$ protein was identified as a dimer by Fando et al. (1985). Using a serum dilution of $1: 400$, as little as $30 \mathrm{ng}$ of restrictocin could be detected with a dot-blot protocol. The antibody produced has an ELISA titre of $1: 4800$, as determined by an antibody dilution series and $50 \%$ of maximal reaction.

\section{Sequence of restrictocin}

The sequence of the restrictocin cDNA contained the coding region of the mature protein; it and our genomic sequence are in agreement with the genomic sequence reported by Lamy \& Davies (1991). The $6.4 \mathrm{~kb}$ fragment of genomic DNA that we cloned contained the entire restrictocin gene between the internal EcoRI site at $1.4 \mathrm{~kb}$ and the HindIII site at $2.5 \mathrm{~kb}$. Other restriction sites identified were $X m a \mathrm{I}$ at $2.0 \mathrm{~kb}$ and $5.5 \mathrm{~kb}$; HindIII, $3.0 \mathrm{~kb}$; BamHI, $3.2 \mathrm{~kb}$; and SacI, $4.8 \mathrm{~kb}$. The cDNA sequence of restrictocin was compared with the cDNA sequence of $\alpha$-sarcin (Oka et al., 1990) and $79 \%$ identity was found in the coding region. The non-coding regions have $39 \cdot 4 \%$ similarity (gap weight $5 \cdot 0$, length weight $0 \cdot 3$ ).

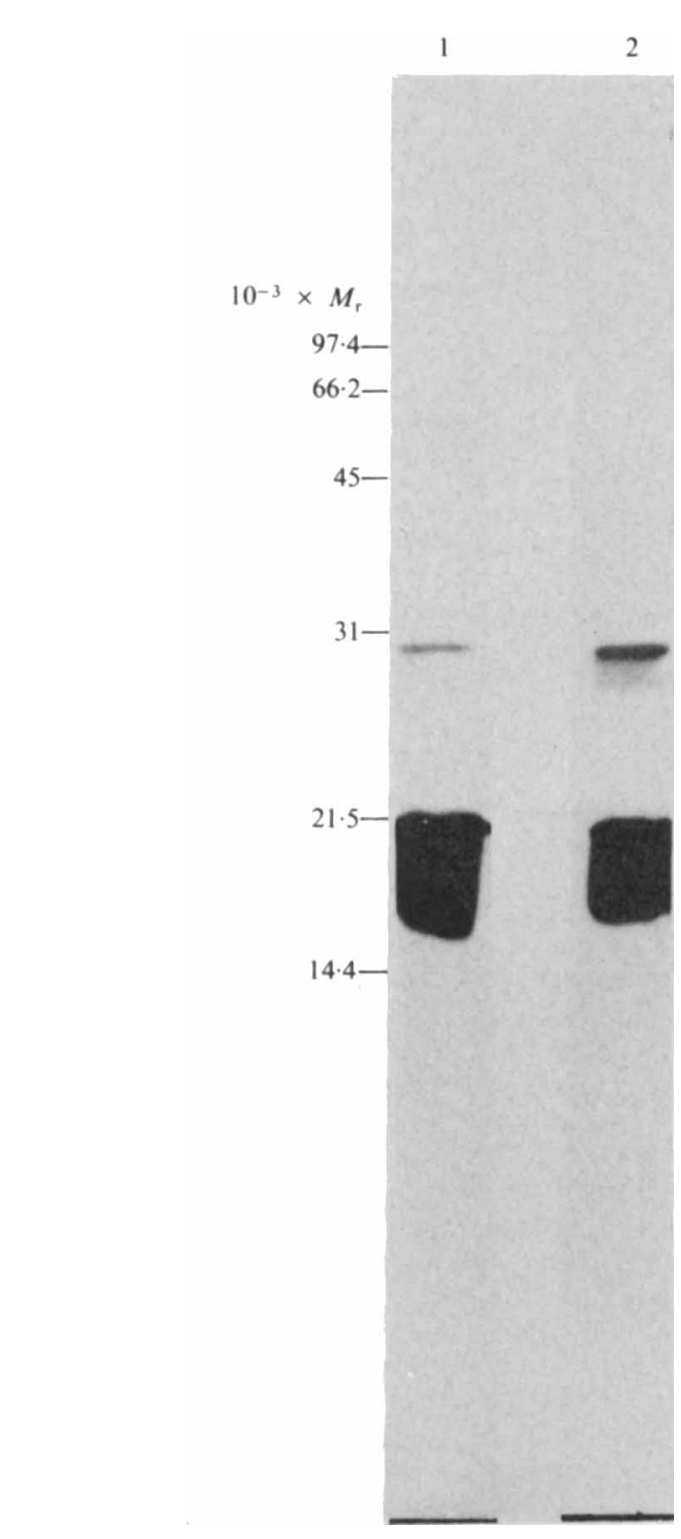

Fig. 1. Silver-stained SDS gel showing purified restrictocin. Lane 1, restrictocin purified by IRC-50 cation-exchange resin; lane 2, restrictocin further purified by membrane filtration. Migration of $M_{\mathrm{r}}$ markers is indicated at the left.

Table 1. Comparison of the leader sequences of A. awamori glucoamylase and A. restrictus restrictocin

\begin{tabular}{lllc}
\hline \hline Protein & \multicolumn{1}{c}{ Signal peptide } & pro Region & $\begin{array}{c}\text { First amino acid } \\
\text {-mature }\end{array}$ \\
\hline Glucoamylase & MSFRSLLALSGLVCTGLA & NVISKR & $\mathrm{A}$ \\
Restrictocin & MVAIKNLFLLAATAVSVLA & APSPLDAR & $\mathrm{A}$ \\
\hline \hline
\end{tabular}




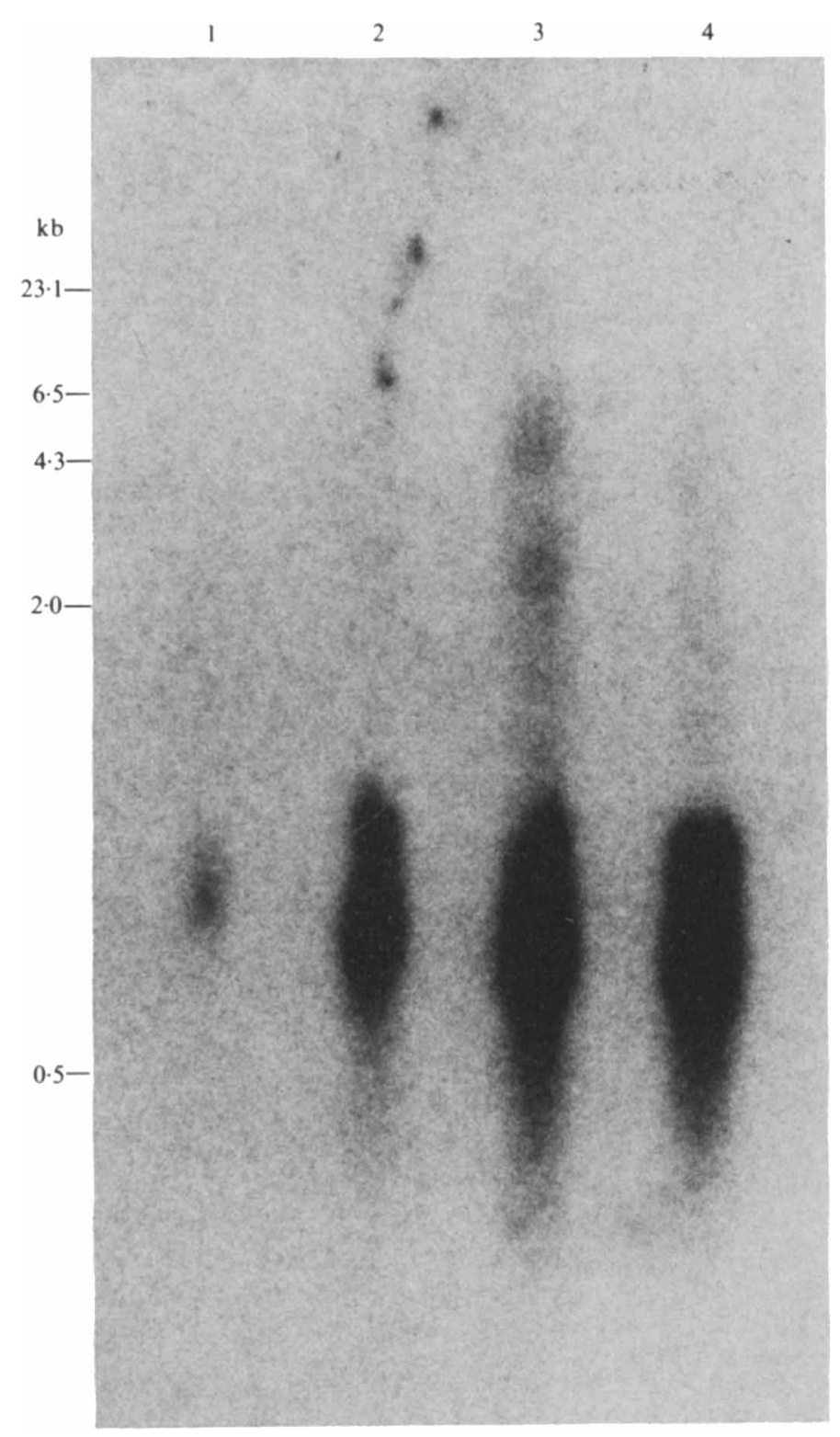

Fig. 2. Northern analysis of the total RNA from $A$. restrictus at different stages of growth. The cDNA fragment was used as a probe. Different amounts of total RNA were loaded: lane 1, 12 h growth; lane 2, $24 \mathrm{~h}$ growth; lane 3, $36 \mathrm{~h}$ growth; lane $4,48 \mathrm{~h}$ growth. Standards are indicated at the left. Ethidium bromide staining and densitometric analysis showed that the ratio of total ribosomal RNA in the four lanes was $4 \cdot 3: 2 \cdot 7: 2 \cdot 1: 1$. Densitometric analysis of the hybridization bands in the four lanes of the autoradiograph gave a ratio of $1: 8 \cdot 6: 11 \cdot 8: 22$.
The manner by which restrictocin is made (and the ribosome making it not being inactivated) is suggested from the cDNA and genomic sequences. A leader sequence (27 amino acids $\mathrm{N}$-terminal to the form found in the medium) is indicated by the genomic and cDNA sequences. The secretion of restrictocin by transformed Aspergillus nidulans (Lamy \& Davies, 1991) indicates that other species of Aspergillus are able to recognize this signal sequence. Efficient secretion of the protein away from the ribosome may protect the ribosome from the action of restrictocin.

Table 1 compares the leader sequence of restrictocin with the leader sequence of glucoamylase from Aspergillus awamori which also contains a potential 'pro' region (Innis et al., 1985). A signal peptidase site was demonstrated in the processing of glucoamylase when it was expressed in the heterologous system of Saccharomyces cerevisiae (Innis et al., 1985). Further processing in $S$. cerevisiae was confirmed when the protein was expressed in a KEX2 mutant that produced glucoamylase with an $\mathrm{N}$-terminal extension of six amino acids. The amino acid sequence before alanine- 18 of glucoamylase contains a hydrophobic region of 13 residues and a basic residue which is directly comparable to that of restrictocin (Table 1). A signal cleavage site after either alanine- 19 or -20 of restrictocin would leave an $\mathrm{N}$ terminal extension of seven to eight amino acids that would have to be removed in further processing (Table 1).

While the signal peptidase and further endoproteolytic processing have never been demonstrated for either of these proteins in the original host, these protein 


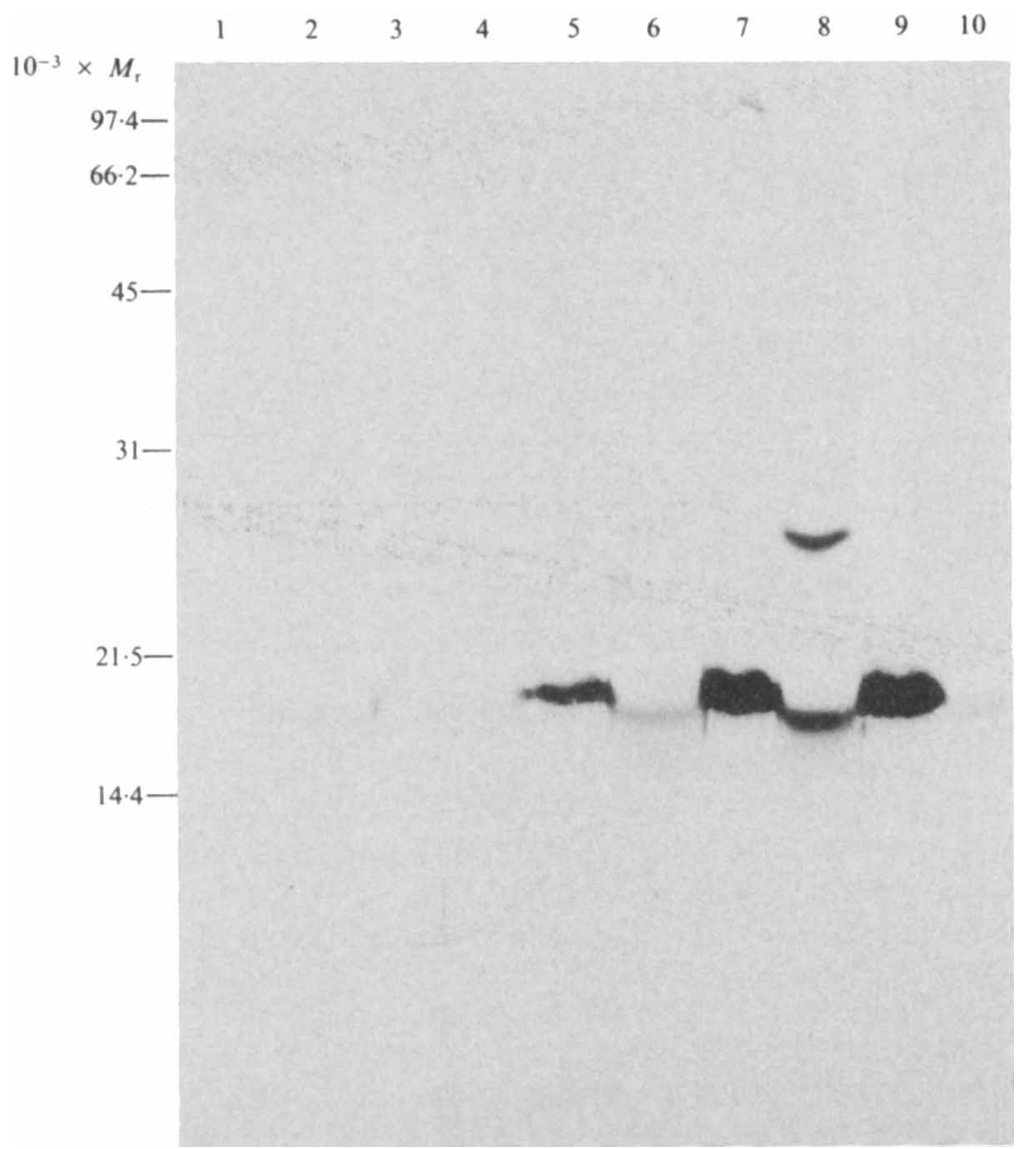

Fig. 3. Immunoblot analysis of proteins secreted and cell-associated at different stages of growth. Lane 1, $25 \mathrm{~h}$ medium; lane $2,25 \mathrm{~h}$ cell; lane $3,35 \mathrm{~h}$ medium: lane $4,35 \mathrm{~h}$ cell; lane $5,47 \mathrm{~h}$ medium; lane $6,47 \mathrm{~h}$ cell; lane 7,60 h medium; lane $8,60 \mathrm{~h}$ cell; lane 9 , $70 \mathrm{~h}$ medium; lane $10,70 \mathrm{~h}$ cell. The samples loaded for cells and medium represented 500 and $50 \mu \mathrm{l}$ of culture respectively. extensions, if present, could serve a variety of purposes. The final destination of a protein in a filamentous host can be quite distal to its point of synthesis. These peptides could serve as a targeting system for the proteins, or in the case of restrictocin it is possible that $\mathrm{N}$-terminal extensions could inactivate the cytotoxin as suggested by Lamy \& Davies (1991). We are conducting further studies to detect $\mathrm{N}$-terminal extensions and their role in protein targeting in $A$. restrictus.

\section{Expression of $m R N A$ and protein production}

Fig. 2 is a representative Northern analysis where only a trace amount of the res mRNA could be detected at $12 \mathrm{~h}$. The res mRNA increased dramatically between 12 and $24 \mathrm{~h}$ and in this experiment reached its highest level at our last time point of $48 \mathrm{~h}$. Densitometric measurements of the photographs of the ethidium-bromide-stained RNA gel and the Northern analysis (Fig. 2) showed that the amount of probe hybridizing increased 14-, 24- and 95 -fold at 24,36 and $48 \mathrm{~h}$ respectively. Significant growth had taken place by $12 \mathrm{~h}$ with germ tubes extending from the germinated conidia.

Immunoblot analysis indicated restrictocin was first detected in both the cell and medium when the res
mRNA was present at detectable levels. In the experiment represented by Fig. 3, the mRNA was already present in the first sample. The amount of detectable restrictocin was higher in the supernatant. However, this is not shown in this immunoblot where the cell sample represented 10 -fold more of the culture than the supernatant. The cell material always contained more restrictocin dimer than did the supernatant. Dissolution of the dimer by SDS might not have been complete in the cell material due to the greater amount of protein in the sample.

The Northern and immunoblot analysis indicated that the mRNA and the protein are made after significant growth has accumulated in the liquid culture and the messenger is probably used and not stored. Most of the protein is secreted into medium. The protein associated with the cells increases with time but not as much as that secreted into the medium.

\section{Microscopy}

Liquid cultures of $A$. restrictus were observed during the entire growth and production curve of restrictocin. In medium containing glucose the germinating conidia aggregated into large balls soon after growth had 

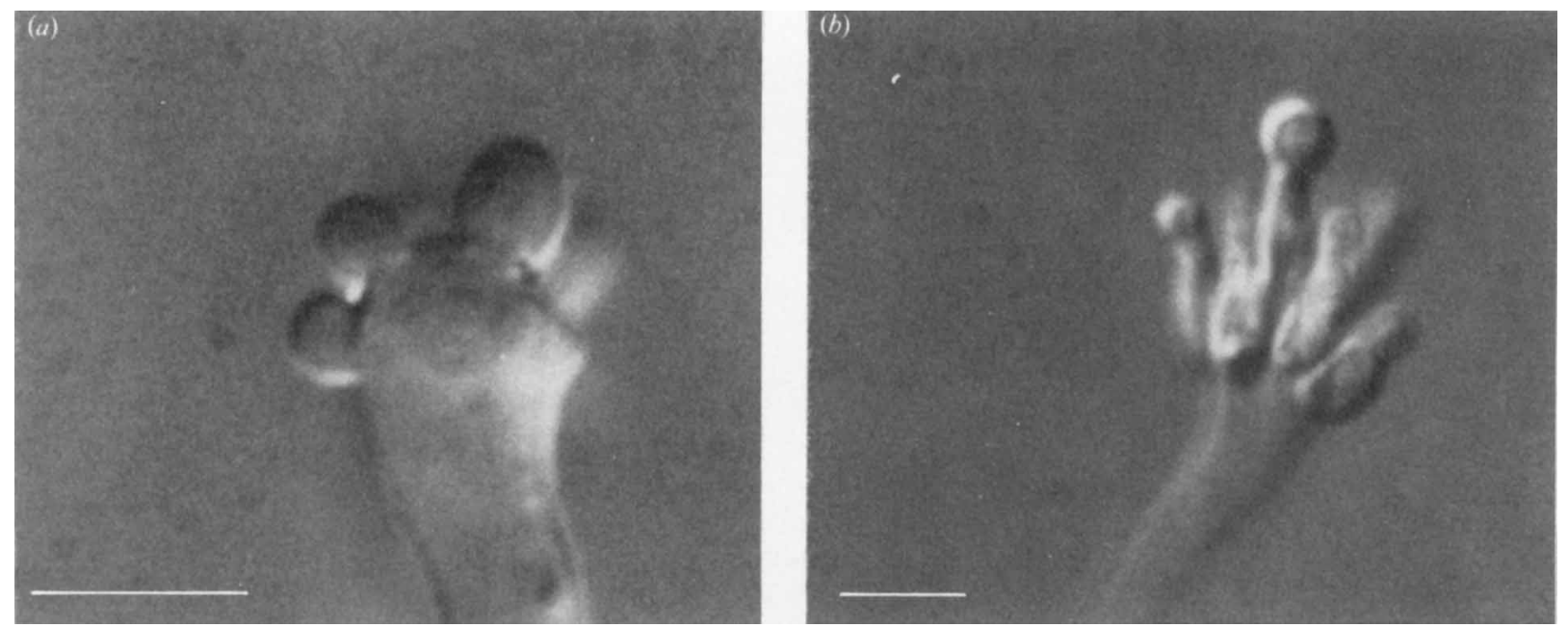

Fig. 4. Differential interference contrast photomicrograph of $A$. restrictus at $24(a)$ and $35 \mathrm{~h}(b)$ of growth. Bars, $5 \mu \mathrm{m}$.

commenced. In medium containing starch this aggregation was much less evident. Hyphal growth was observed following germination and after 25 to $35 \mathrm{~h}$ an enlargement of the hyphal tip, with branching near the tip, could be observed on some of the hyphae in the culture (Fig. 4). Often these would also contain a second layer of cells, also as shown in Fig. 4. Differentiated structures that are similar to conidiophores, sterigmata and conidia (Thom \& Raper, 1945) were observed in submerged cultures of $A$. restrictus. These structures can be observed in the hyphae that remain free in the medium and are not just associated with hyphae that have stuck to the sides of the vessel.

In the experiment reported in Fig. 3, enlarged hyphal tips that had started to branch were observed at $25 \mathrm{~h}$ and complete differentiation was first observed in the $35 \mathrm{~h}$ sample. Upon continued incubation, some of these extensions would undergo further growth and result in a slightly longer hyphal filament that died and lysed after this extension. When differentiation first started the differentiated structures were rare in the culture. By the time restrictocin was very evident as detected by immunoblot, as many as $50 \%$ of the observed hyphal tips on the edges of clumps had differentiated.

In more than 10 growth experiments analysed, the presence of differentiated structures was observed in the samples when restrictocin accumulated in the medium. We have also observed similar structures and timing of $\alpha$ sarcin appearance in cultures of $\boldsymbol{A}$. giganteus (data not shown). In the four experiments where mRNA was analysed, along with protein production, the first evidence of res mRNA was when these differentiated structures could be observed. The mRNA from cultures that did not yet contain these structures did not have
RNA bands that hybridized significantly with the probe, and maximum mRNA and protein accumulation correlated with the highest frequencies of differentiated structures.

\section{Conclusions}

The results from our studies show that restrictocin is produced only after significant growth of $\boldsymbol{A}$. restrictus has taken place. This is common with many toxic secondary metabolites produced by filamentous fungi. The accumulation of restrictocin in the medium is coincident with the appearance of both mRNA and differentiated structures in the culture. The results suggest that restrictocin is coordinately regulated with, or involved in, the process of conidiation.

The question of the function of restrictocin in Aspergillus remains unanswered. The appearance of the protein in the medium coordinate with the synthesis of mRNA precludes a hypothesis of storage of the protein in some inactive form. Restrictocin is made in cultures undergoing differentiation in liquid medium. It is possible that these structures would have restrictocin associated with them if they were formed by growth on solid medium. Also the protein itself could be involved in the selective inactivation of fungal cells in the culture.

A survival advantage might be conferred on the fungus by the production of restrictocin during the process of conidiation. If the conidiophore or associated cell structures have restrictocin associated with them then insect predation might be deterred. The protein might also kill an insect by inactivating cells in the digestive system and the conidia that were present could germinate and grow on the insect. 
An alternative function can be proposed for restrictocin. A restrictocin-like protein could cause inflammation and local cell death in Aspergillosis infections (Arruda et al., 1990). If restrictocin is involved in the invasion of the lungs, the protein should already be present on the initial particles deposited in the lung. Our results indicate that initial growth of the fungus in the lung cannot be assisted by the inflammation provided by restrictocin unless the protein is formed quickly in the lungs. Arruda et al. (1991) have indicated that a restrictocin-like protein in Aspergillus fumigatus cultures requires growth of the fungus and is not localized on the conidia.

Experiments to determine the cellular location of restrictocin in cells from liquid or solid medium and the conditions that regulate restrictocin production should provide important information on the function of this protein. The accompanying paper (Brandhorst \& Kenealy, 1992) reports experiments on the cellular location of restrictocin.

We thank $\mathrm{T} . \mathrm{K} . \mathrm{Ng}$ for supplying the culture of $A$. restrictus, and $\mathrm{T}$. Morrical for characterizing the rabbit antiserum. Special thanks to the Biochemistry Fermentation Pilot Plant for assistance in large scale culture of $\boldsymbol{A}$. restrictus and purification of restrictocin. This research was supported by the College of Agricultural and Life Sciences and by a Steenbock Career Development Award, University of Wisconsin, Department of Biochemistry.

\section{References}

Arruda, L. K., Platts-Mills, T. A. E., Fox, J. W. \& Chapman, M. D. (1990). Aspergillus fumigatus allergen I, a major IgE-binding protein, is a member of the mitogillin family of cytotoxins. Journal of Experimental Medicine 172, 1529-1532.

Arruda, L. K., Good, M., Platts-Mills, T. A. E. \& Chapman, M. D (1991). Asp FI, a major Aspergillus fumigatus allergen: homology to the cytotoxin mitogillin and measurements in spore, mycelial and culture filtrate extracts. Journal of Allergic and Clinical Immunology $87,168$.

Ausubel, F. M., Brent, R., Kingston, R. E., Moore, D. D., Seidman, J. G., Smith, J. A. \& Struhl, K. (1987). In Current Protocols in Molecular Biology. Edited by F. M. Ausubel, R. Brent, R. E. Kingston, D. D. Moore, J. G. Seidman, J. A. Smith \& K. Struhl. USA: Green Publishing Associates and Wiley-Interscience.

Brandhorst, T. T. \& Kenealy, W. R. (1992). Production and localization of restrictocin in Aspergillus restictus. Journal of General Microbiology 138, 1429-1435.

COVE, D. J. (1966). The induction and repression of nitrate reductase in the fungus Aspergillus nidulans. Biochimica et Biophysica Acta 113, 5156.
Fando, J. L., Alaba, I., Escarmis, C., Fernandez-luna, J. L., MENDEZ, E. \& Salinas, M. (1985). The mode of action of restrictocin and mitogillin on eukaryotic ribosomes. European Journal of Biochemistry 149, 29-34.

Goldin, A., Serpick, A. A. \& Mantel, N. (1966). Experimental screening procedures and clinical predictability value. Cancer Chemotherapy Reports 50, 173-218.

InNis, M. A., Holland, M. J., McCabe, P. C., Cole, G. E., Wittman, V. P., Tal, R., Watt, K. W. K., Gelfand, D. H., Holland, J. P. \& MeADE, J. H. (1985). Expression, glycosylation and secretion of an Aspergillus glucoamylase by Saccharomyces cerevisiae. Science 228, 21-26.

JAKES, K. S. \& ZINDER, N. D. (1974). Highly purified colicin E3 contains immunity protein. Proceedings of the National Academy of Sciences of the United States of America 71, 3380-3384.

LAEMMLI, U. K. (1970). Cleavage of structural proteins during the assembly of the head of bacteriophage T4. Nature, London 227, 680685.

LAMY, B. \& DAVIES, J. (1991). Isolation and nucleotide sequence of the Aspergillus restrictus gene coding for the ribonucleolytic toxin restrictocin and its expression in Aspergillus nidulans: the leader sequence protects producing strains from suicide. Nucleic Acids Research 19, 1001-1006.

Lopez-Otin, C., Barber, D., Fernandez-luna, J. L., Soriano, F. \& MENDEZ, E. (1984). The primary structure of the cytotoxin restrictocin. European Journal of Biochemistry 143, 621-634.

Miller, S. P. \& BoDley, J. W. (1988). The ribosomes of Aspergillus giganteus are sensitive to the cytotoxic action of $\alpha$-sarcin. FEBS Letters 229, 388-390.

Oka, T., Natori, Y., Tanaka, S., Tsurugi, K. \& Endo, Y. (1990). Complete nucleotide sequence of cDNA for the cytotoxin alpha sarcin. Nucleic Acids Research 18, 1897.

Olson, B. H., HaRveY, C. L. \& JuneK, A. J. (1963). US patent \#3104208.

Olson, B. H., Jennings, J. C., Roga, V., Junek, A. J. \& Schuurmans, D. M. (1965). Alpha sarcin, a new antitumor agent. II. Fermentation and antitumor spectrum. Applied Microbiology 13, 322-326.

Roga, V., Hedeman, L. P. \& Olson, B. H. (1971). Evaluation of mitogillin (NSC-69529) in the treatment of naturally occurring canine neoplasms. Cancer Chemotherapy Reports 55, 101-113.

SANGer, F., Nicklen, S. \& Coulson, R. (1977). DNA sequencing with chain terminating inhibitors. Proceedings of the National Academy of Sciences of the United States of America 74, 5463-5467.

SChindler, D. G. \& Davies, J. E. (1977). Specific cleavage of ribosomal RNA caused by alpha sarcin. Nucleic Acids Research 4, 1097-1110.

Sperti, S., Zamboni, M., Brigotti, M., Rambelli, F. \& Montanaro, L. (1989). Alpha-sarcin impairs the N-glycosidase activity of ricin on ribosomes. Biochemical and Biophysical Research Communications 160, 857-861.

Thom, C. \& RAPER, K. B. (1945). A Manual of the Aspergilli. Baltimore: Williams and Wilkins.

WoOL, I. G. (1984). The mechanism of the action of the cytotoxic nuclease $\alpha$-sarcin and its use to analyse ribosome structure. Trends in Biochemical Sciences 9, 14-17.

Wray, W., Boulikas, T., Wray, V. P. \& HaNCOCK, R. (1981). Silver staining of proteins in polyacrylamide gels. Analytical Biochemistry 118, 197-203. 